\title{
Consonantismo avanzado en Madrid entre los siglos XVI y XIX a partir de un corpus documental (ALDICAM-CM)*
}

\author{
Innovative consonantism in Madrid between the sixteenth and \\ nineteenth centuries from a documentary corpus
}

\author{
Pedro Sánchez-Prieto Borja \\ Delfina VázQuez Balonga \\ Universidad de Alcalá
}

\begin{abstract}
Resumen. Para explicar la historia del consonantismo madrileño, es necesario considerar también el estado actual del español. Suele atribuirse a la inmigración meridional del s. Xx el carácter innovador en muchos rasgos en los sociolectos medios y bajos de la ciudad. Por tanto, hay que rastrear en la documentación archivística para determinar si tales usos son relativamente recientes o tienen sus raíces en el habla madrileña de siglos anteriores. Esto es posible gracias al uso de fuentes que atestigüen los empleos de las clases populares: peticiones a las instituciones benéficas y otros escritos.

Entre los rasgos encontrados en el consonantismo, el más sorprendente es el indicio gráfico de seseo, documentado en los ss. XVI-XIX. La documentación de estos y otros fenómenos avanzados en la escritura del estrato popular y medio, y no solo en la localidad de Madrid, sino incluso en zonas rurales, obliga a replantear la posición histórica del consonantismo madrileño.
\end{abstract}

Data de recepción: 15-11-2018 - Data de aceptación: 10-04-2019.

* Este trabajo se ha realizado dentro del marco de los proyectos «ALDICAM-CM» (S2015/ HUM3443), financiado por la Comunidad de Madrid. aldicam.blogspot.es y «Corpus de Documentos Españoles Anteriores a 1900» (FFI2017-82770-P), financiado por el Ministerio de Economía y Competitividad. 
Palabras clave: Madrid, consonantismo, documentos de archivo, sociolingüística diacrónica.

Abstract. To explain the history of consonantism in Madrid, it must be consider the actual state of Spanish language. It is usually attributed to south inmigration during the 20th century the innovative characteristics in middle and lower sociolects. So archival documents must be analyse to determine if linguistic uses are quite recent or have developed in Madrid before. This is possible by using sources that could show linguistic uses of underclass, like requests to charity institutions and other documents.

The graphical sign of «seseo» (16th-19th century) is the most surprising of all consonantic characterics. This and other innovative linguistic phenomena in lower and middle class writing, not only in Madrid, but also in villages, make consider again the historic status of consonantism in Madrid.

Keywords: Madrid, consonantism, archival documents, diachronic sociolinguistics.

\section{INTRODUCCIÓN}

\subsection{Lo urbano y lo rural}

Un aspecto implícito en el estudio de las hablas de la Comunidad de Madrid es la oposición entre lo urbano y lo rural. En el primer ámbito, destaca la variedad sociolingüística de la ciudad de Madrid, estudiada en diversos trabajos de los últimos años, entre los que sobresale el proyecto PRESEEA, que lleva a cabo encuestas en la capital, y que ha dado lugar a algunas publicaciones destacadas (Molina Martos, Cestero, Paredes 2015). Acerca de las zonas rurales de la CM, se pueden mencionar el proyecto $A D i M(2015)$ y las publicaciones derivadas del mismo (García Mouton y Molina Martos 2017). Sobre las zonas rurales de la región, se han señalado algunas diferencias comarcales (vid. 2). Un fenómeno que ha cambiado por completo la configuración dialectal de la Comunidad de Madrid ha sido la influencia de la capital en el habla de las localidades rurales, de acuerdo con un proceso que se ha podido demostrar en algunos fenómenos fonéticos, como el auge del yeísmo (Molina Martos 2013).

\subsection{Estudios sobre el habla de Madrid en el pasado}

En cuanto a la historia del habla de Madrid, se ha acudido, sobre todo, a fuentes literarias; las más citadas, para los ss. XVIII, XIX y XX, respectivamente, son las obras de Ramón de la Cruz, Galdós y Arniches. En concreto, para la segunda mitad del siglo XIX, es interesante adentrarse en la caracterización lingüística de los personajes 
madrileños de Galdós, sobre todo en los tipos más populares, de los que se hace un cuidado retrato lingüístico. Destacamos por su detallismo en este aspecto una obra poco conocida, Los madrileños adoptivos (1790), de Antonio González de León, cuyos personajes presentan rasgos como la vacilación de vocales átonas (menistro) y, sobre todo, fenómenos consonánticos: trueque de líquidas (frábica) y de otras consonantes (estógamo), pérdida de [-d] (usté).

Si dejamos aparte la Edad Media y las ediciones del Fuero de Madrid (h.1200; Millares Carlo et al. 1932) y Fuero de Alcalá (anterior a 1247, Torrens Álvarez 2002), han sido pocos los estudios sobre la evolución histórica del habla de Madrid, con alguna excepción (Bustos Gisbert y Santiago 2000). Más recientemente, han aparecido recopilaciones y estudios de documentos de archivo emitidos en localidades de la región: Alcalá de Henares (Almeida Cabrejas 2014; Paredes García 2005), Arganda del Rey (Vázquez Balonga 2014), Daganzo (Paredes García 2010) y Madrid capital (Sánchez-Prieto Borja 2005; Vázquez Balonga y Sánchez-Prieto Borja 2015; SánchezPrieto Borja y Vázquez Balonga 2017, 2018).

\section{VARIACIÓN SOCIOLINGÜÍSTICA Y GEOGRÁFICA EN LA COMUNIDAD DE MADRID}

Para paliar estas carencias hemos emprendido el proyecto ALDICAM-CM, cuyo objetivo es examinar la lengua de Madrid a partir de un corpus de documentos conservados en archivos de la Comunidad. En él se incluyen muestras desde la Edad Media al siglo XIX, tanto de la capital como de localidades de los cuatro puntos cardinales de la región. Tienen un especial interés los documentos que transparentan usos habituales del scriptor en el nivel fónico. Para abordar el estudio diacrónico de la fonética madrileña, y en concreto del consonantismo, debemos distinguir los fenómenos que se producen de las siguientes formas:

1) Por mano inhábil. De esta manera denominamos a la propia de un scriptor poco alfabetizado. Por tanto, sus rasgos gráficos se consideran marcadores sociolingüísticos de nivel bajo. Un ejemplo de ello es guchillo 'cuchillo' (confusión de /k/ y /g/) o reitos 'réditos' (omisión de -/d/).

2) Según el uso gráfico-fonético general de la época, incluso en mano profesional de escribanos. Este sería el caso de toballa, tobaja 'toalla' o setiembre 'septiembre'.

Los rasgos del primer grupo, por lo tanto, se encontrarán en documentos hechos dentro de un grupo sociolingüístico bajo, y son visibles, por ejemplo, en solicitudes de ayuda a las instituciones benéficas, sobre todo de la ciudad de Madrid, como notas, peticiones de juicio verbal, recibos y otros documentos en los que manos no 
profesionales se ven obligadas a escribir. También hay que incluir a algunos empleados municipales con escaso dominio gráfico. Por el contrario, en el segundo grupo tendremos una amplia tipología que incluye las piezas elaboradas por profesionales de la escritura, como notarios y otras personas letradas: denuncias, testamentos, notificaciones municipales, informes, entre otros.

En un plano diferente, el de la configuración geográfica del territorio estudiado, partimos de tres ideas principales. La primera es la consideración como punto de partida del concepto de «tierra de Madrid», denominación histórica referida a un territorio que abarca, aproximadamente, la actual Comunidad, con una base dialectal común. En segundo lugar, Madrid capital, que fue foco de innovaciones lingüísticas hacia zonas más cercanas dentro de la Comunidad. Al mismo tiempo, a partir de la capitalidad en 1561, recibió un flujo de población nueva que contribuiría a la conformación de las hablas populares de la ciudad. Además, debido a las relaciones económicas, el contacto entre habitantes de la capital y los pueblos cercanos será cada vez más intenso, sobre todo desde el s. XVIII.

La región de Madrid ha sido una frontera lingüística entre el centro-norte y centro-sur. Esto ha sido probado con el estudio reciente de los documentos archivísticos, que ha permitido constatar la existencia en la Comunidad hasta el siglo XVIII del llamado «neutro de materia» (lana blanco en Daganzo en 1594; plata falso en Arganda del Rey en 1677) (Gómez Seibane y Vázquez Balonga 2013; Vázquez Balonga 2015) De hecho, algunas voces parecen ser de uso restringido en algunas comarcas de la región y no se han registrado en otras provincias o áreas lingüísticas. Así se ve en el estudio de la documentación de ALDICAM con ejemplos como pasto siego, término solo encontrado en Hoyo de Manzanares (1706) y zerbigajo (Alcalá de Henares, $1549)^{2}$, con sus variantes cerviajo 'borde alto de un camino' (Daganzo, 1782) y recogida recientemente como cerribajo (Arganda del Rey, Alvar Ezquerra 2011).

Como se ha apuntado, la conformación de la región como red económica es un factor de contacto lingüístico de gran importancia entre la capital y los pueblos. Muchas localidades madrileñas surtían a la villa y corte de determinados productos: Alcorcón (vidriado de barro desde el siglo XVI), Hoyo de Manzanares (carbón, leña, granito desde el XVII), Rascafría (madera y leña), Arganda del Rey (vino y aceite),

1 En la Sierra Norte se ha localizado esta concordancia en incontables en el siglo XIX (manteca salado en Buitrago del Lozoya, h. 1831). Prueba de su progresivo declive es manteca salada en Montejo de la Sierra en 1894 (ALDICAM). Por último, en encuestas recientes del COSER se hallan testimonios en hablantes de avanzada edad en Horcajo de la Sierra, en la misma comarca (manteca (...) rancio) (Fernández-Ordóñez 2006).

2 «A otro mojón qu'esta en un zerbigajo a la mano izquierda» (ALDICAM 16). 
Navalcarnero (vino) y Cadalso de los Vidrios (productos del vidrio), entre otros. A partir del s. XIX, gracias a la conservación de pasaportes en algunos archivos, se puede constatar la gran afluencia de viajeros desde zonas periféricas de la CM, como la Sierra Norte, hacia Madrid capital. Este es el caso de Buitrago del Lozoya, localidad de la Sierra Norte aparentemente aislada, en la que se emiten numerosos pases en la década de 1830 para personas que justifican su salida para ir a servir, trabajar, pedir limosna o curarse ${ }^{3}$.

También en esta localidad, situada en el camino de Francia, fueron constantes en el s. XIX el paso y establecimiento temporal de guarniciones militares, francesas primero y, luego, españolas, con un contacto continuo con la población, obligada al aprovisionamiento de las tropas, asunto sobre el que han quedado numerosos testimonios escritos. Tampoco hay que olvidar la trashumancia de ganados hacia Segovia desde La Mancha, así como otros movimientos cortos, buscando pastos de verano. Ha quedado evidencia de la trashumancia en la zona norteña; así, en Montejo de la Sierra se citan en un inventario «cuatro cabras que fueron a Extremadura» $(761,1856)$.

No obstante, y sin olvidar el desarrollo interno, cabe señalar también diferencias geolingüísticas en la CM, debido al contacto con zonas limítrofes. De acuerdo con Moreno Fernández (2004), la región de Madrid está incluida en Castilla La Nueva y se divide en tres zonas dialectales: occidental (influida por Segovia), oriental (por Guadalajara) y meridional (por Toledo); por tanto, Madrid sería una zona de transición con diversos rasgos lingüísticos comunes al área central, pero, a la vez, diversos según su área de influencia ${ }^{4}$. En un análisis de la documentación de ALDICAM se encontraron algunas voces que se vinculaban con una zona centro-norte y otras con el centro-sur (Sánchez-Prieto Borja y Vázquez Balonga, 2018). Un ejemplo es corte 'pocilga', encontrada en un documento de Camarma de Esteruelas (1765), una localidad cercana a la provincia de Guadalajara, donde, precisamente, se localiza este término con idéntico significado (ALeCMan) .

Igualmente, García Mouton y Molina Martos (2017: 28) establecen una distinción entre zonas geográficas a partir de algunos tratamientos fonéticos; así, la /d/ implosiva final tiende a articularse como interdental en el norte y a perderse en el sur; por otra

3 Por ejemplo, en 1832, Manuel Albín, natural de Asturias, que se dirige a Madrid a buscar empleo, o Feliciana Durán, natural del pueblo, que va a la capital como sirvienta (Archivo Municipal de Buitrago del Lozoya, caja 19, 3).

$4 \quad$ El autor menciona el caso de la neutralización de líquidas, más viva en el este por influencia de la provincia de Guadalajara (2004).

5 Además, corte se encuentra en las encuestas actuales de Madrid, también en zonas del este, como Paracuellos y Talamanca del Jarama (Ruiz Martínez 2000; Alvar Ezquerra 2011). 
parte, el yeísmo se da en el sur, mientras que en el norte quedan los pueblos conservadores, que distinguen /y/-/ $/ \lambda$ (ibídem: 19). Asimismo, en la zona meridional se da el yeísmo y una mayor relajación de la [-s] implosiva, tanto interior como final. Por el contrario, fenómenos como el debilitamiento de [-d-] (tostao, trabajá) se encuentran ahora generalizados en la región.

\section{EL PROYECTO ALDICAM-CM}

El corpus ALDICAM se conforma dentro la línea de investigación del Grupo de Investigación de Textos para la Historia del Español (GITHE) de la Universidad de Alcalá y sirve de base para elaborar un atlas diacrónico articulado en torno a dos planos, geográfico y cronológico. De la consideración de ambos se espera una mayor comprensión de los fenómenos evolutivos del español en todas sus variedades. Por este motivo, se ha querido aprovechar el que los documentos estén provistos de data topica para poner de relieve las diferencias geográficas, cambiantes a lo largo del tiempo, en las que se va configurando el dominio hispánico. Los logros alcanzados hasta ahora se han materializado en dos dominios específicos: 1) el hispánico peninsular, representado por $C O D E A^{6}$, y 2) el restringido a una región, en nuestro caso, la CM (ALDICAM) 7 . En la actualidad, este último corpus cuenta con 773 documentos transcritos de 54 localidades diferentes. Los archivos de procedencia son el Archivo Regional de la Comunidad de Madrid, el de Villa, el Histórico Nacional y el de Protocolos, junto a 19 archivos municipales. La localidad más presente es Madrid capital, por su elevada cantidad de documentos emitidos y conservados. Otras poblaciones destacadas son Daganzo de Arriba (45 documentos), El Escorial (39) y Alcalá de Henares (37). En cuanto al abanico cronológico, la mayoría de los documentos pertenecen a los siglos XVI-XVIII (Figura 1).

\begin{tabular}{|c|c|c|c|}
\hline s. $\mathbf{X V I}$ & s. XVII & s. XVIII & s. XIX \\
\hline 247 & 162 & 206 & 141 \\
\hline
\end{tabular}

FIGURA 1. Número de documentos por siglo

Actualmente se está desarrollando, en colaboración con la Universidad de Tokio, la aplicación informática que permitirá la consulta interactiva del corpus y la visualización inmediata de las consultas. Puede verse un prototipo del mapa de localidades

http://www.corpuscodea.es

http://aldicam.blogspot.com/ 
en las que se emiten documentos (Figura 2), mientras que, a continuación, se muestra la localización en Camarma de Esteruelas y Alcorcón de los resultados del término de búsqueda mulo (Figura 3$)^{8}$.

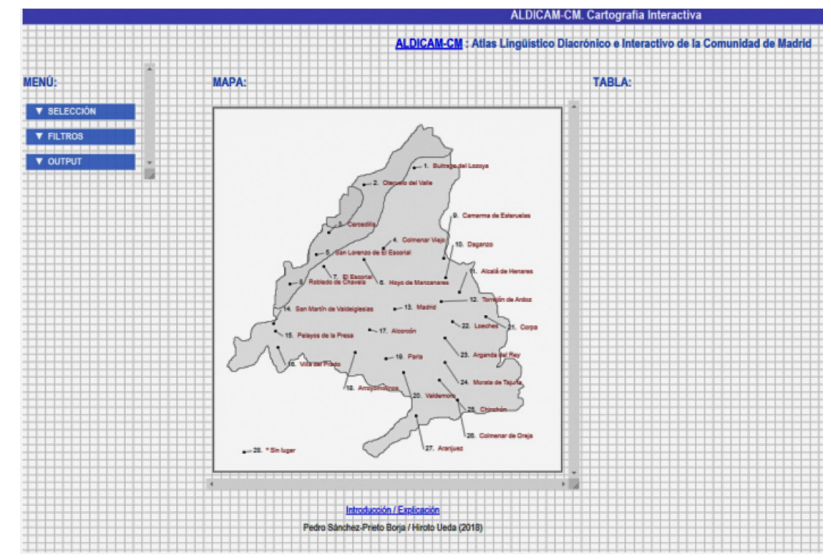

Figura 2. Prototipo de ALDICAM

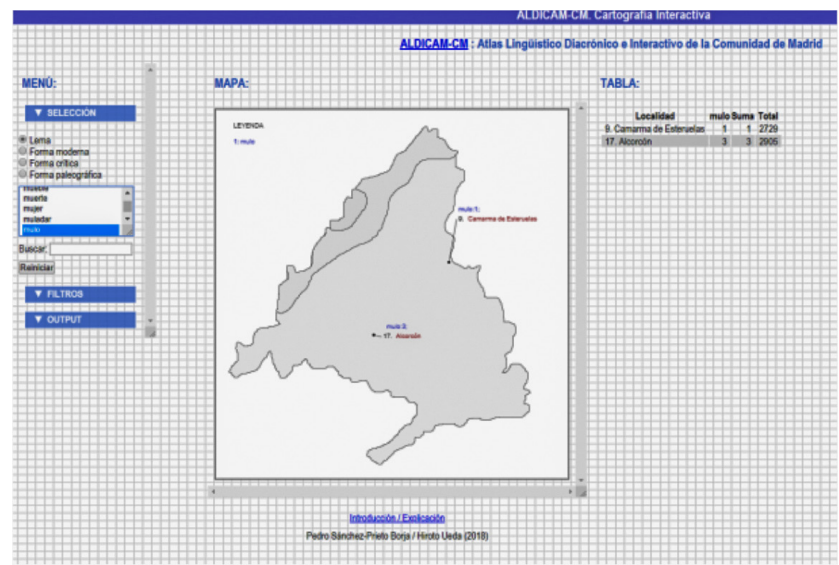

FigurA 3. Resultados de mulo en el prototipo de ALDICAM

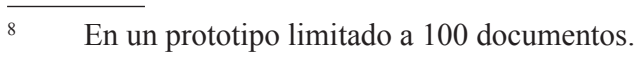




\subsection{Corpus de la ciudad de Madrid}

Los documentos editados y estudiados de la ciudad de Madrid pertenecen, principalmente, a instituciones benéficas establecidas en la ciudad. Su división por nombre de institución, archivo y época es la siguiente (Figura 4).

\begin{tabular}{|l|c|c|c|}
\hline Institución benéfica & Archivo & Siglos & Número de piezas \\
\hline Inclusa de Madrid & ARCM & XVI-XIX & 250 \\
\hline Hermandad del Refugio & $\begin{array}{c}\text { Archivo de la Hermandad del } \\
\text { Refugio (depósito ARCM) }\end{array}$ & XVII-XIX & 196 \\
\hline Colegio de San Ildefonso & Archivo de Villa de Madrid & XVII-XVIII & 28 \\
\hline La Latina & Archivo de Villa de Madrid & XVIII & 3 \\
\hline Asilo de San Bernardino & Archivo de Villa de Madrid & XIX & 2 \\
\hline
\end{tabular}

FiguRA 4. Documentos de la ciudad de Madrid (instituciones benéficas)

Estos documentos presentan una variada tipología: cartas de prohijamiento (adopción), recibos, solicitudes de ayuda, notas de abandono de niños, certificados de bautismo, listados, nombramientos, cartas privadas, informes médicos, informes de obras, inventarios de bienes, cuentas, etc. El documento que resulta más valioso para el estudio de la lengua popular es la nota de abandono, por estar elaborada en bastantes ocasiones por personas que no habían completado su alfabetización y que escribían por unas circunstancias extraordinarias. A título de ejemplo, mostramos la nota de abandono de Vicente Álvarez (Figura 5). Como se puede observar, la letra de esta nota es claramente irregular por sus diferencias de módulo y la disposición torcida. Además del aspecto gráfico, llama la atención algunos fenómenos como la confusión de diptongos (boictizado) y errores gráficos como menes tener por menester tener.

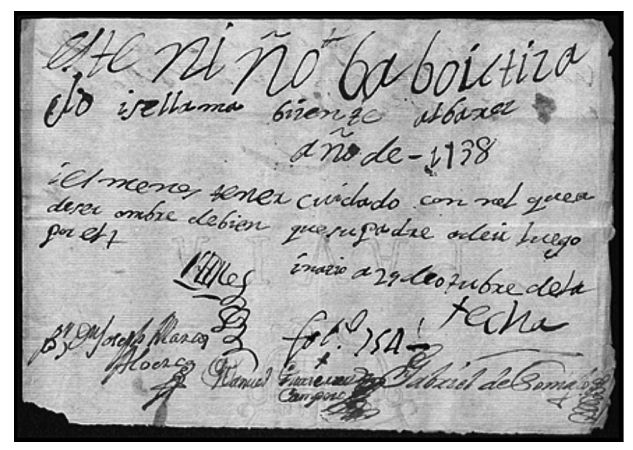

Figura 5. Nota de de abandono de Vicente Álvarez (1738) 
He aquí su presentación íntegra, con cabecera, transcripción paleográfia y presentación crítica:

0365

ALDICAM

1738 s.m. s.d. (s.l. [Madrid, Madrid, España])

ARCM, Hermandad del Refugio, 281-001

Nota de abandono de Vicente Álvarez.

Privado

Nota

infancia, beneficencia

TRANSCRIPCIÓN PALEOGRÁFICA

$\{\mathrm{h} 1 \mathrm{r}\}\{1\}$ este niño ba boictiza $\{2\}$ do i se llama bizente albarez $\{3\}$ año de 1738

$\{4\}$ i es mene tener cuidado con nel quea $\{5\}$ deser ombre debien que su padre adeir luego $\{6\}$ por el $[\mathrm{cruz}] * * * *$ [rúbrica] i nazio a 29 deotubre dela $\{7\}$ fecha

[mano 2: fol $<$ io $>754$ ]

[firma: $\mathrm{B}<$ achiller $>\mathrm{D}<\mathrm{on}>$ Joseph Marcos $\mid$ Alverco] [rúbrica]

[firma: Manuel Gutierrez | Campero] [rúbrica]

[firma: Gabriel de Somalo] [rúbrica]

\section{PRESENTACIÓN CRÍTICA}

$\{\mathrm{h} 1 \mathrm{r}\}\{1\}$ Este niño ba boitiza $\{2\}$ do y se llama Bizente Álbarez, $\{3\}$ año de $1738 .\{4\}$ $\mathrm{Y}$ es menes $<$ ster $>$ tener cuidado con él, que á $\{5\}$ de ser ombre de bien, que su padre á de ir luego $\{6\}$ por él. Y nazió a 29 de otubre de la $\{7\}$ fecha.

Folio 754.

Bachiller don Josep Marcos | Alverco.

Manuel Gutiérrez Campero.

Gabriel de Somalo.

\subsection{Corpus de zonas rurales de Madrid}

Aparte de la capital, los documentos se reparten en 53 localidades de procedencia. Muchos de ellos se conservan en archivos municipales, pero también en el Archivo Regional de la Comunidad de Madrid (ARCM), donde se encuentran algunos fondos locales, como los de Camarma de Esteruelas, Robledo de Chavela o Rascafría. Se ha procurado hacer una distribución equilibrada por zonas, de manera que contamos con localidades de la Sierra Norte (Rascafría, Buitrago del Lozoya, Montejo de la Sierra, La Hiruela, Garganta de los Montes, entre otros), de la Sierra Oeste 
(El Escorial, Guadarrama), la Comarca de Alcalá, en el este (Arganda del Rey, Camarma de Esteruelas, Loeches, Daganzo) y la zona sur (Aranjuez, Navalcarnero, Chinchón, Valdemoro).

Por su valor para conocer el consonantismo avanzado, hemos tenido en cuenta la documentación disponible elaborada por personas de nivel sociocultural bajo, aunque cabe establecer diversos niveles; así, podemos citar un pasquín contra personajes locales (El Escorial, h. 1770), quizá el caso más notorio de mano poco habituada a la escritura; también el corpus dispone de otras muestras igualmente valiosas para documentar fenómenos de la lengua hablada, como una carta escrita desde La Hiruela, en la Sierra Norte madrileña, en 1808 (712). Otras, escritas con más pericia gráfica, transparentan también usos de la lengua popular que hemos analizado aquí.

La tipología documental es, como en la ciudad de Madrid, variada: denuncias, declaraciones, juicios verbales, solicitudes, recibos, inventarios de bienes, órdenes de requisamiento para el ejército, órdenes de captura de delincuentes (bandoleros), informes, entre otros. Las solicitudes tienen especial interés para mostrar los fenómenos fonéticos más alejados de la norma. Incluso entre algunos empleados municipales podía encontrarse un nivel de dominio de la escritura más bajo que los habituales de la capital9.

\section{CONSONANTISMO AVANZADO EN LA DOCUMENTACIÓN MADRILEÑA}

La primera cuestión que debemos afrontar es por qué hemos elegido el consonantismo como objeto de estudio. La razón es que se trata de una parcela de la fonética de gran complejidad, sometida a notable variación, tanto cronológica como geográfica, así como sociolingüística ${ }^{10}$. Por el contrario, los fenómenos de variación del vocalismo son relativamente reducidos y afectan sobre todo a las átonas, usos más difíciles de anclar geográficamente, ya que se trata de fenómenos generales en el amplio espacio del español, repetidos en la documentación de diversas zonas y épocas.

La segunda cuestión debatida es el concepto mismo de «consonantismo innovador», pues se incluyen en este fenómenos de largo recorrido, cuya cronología es a veces difícil de establecer. Puede definirse como el conjunto de rasgos consonánticos alejados de la norma, y en él incluimos usos que acabarán siendo percibidos como «vulgares», como la pérdida de /d/ intervocálica (ceula por cédula, pedio por pedido).

9 Un ejemplo es una carta escrita por el fiel de fechos de la Hiruela al ayuntamiento de Buitrago del Lozoya en 1808: «certifico cómo en este pueblo no ay ninguna arma de fuego ni larja ni corta, ni tampoco otra ninguna arma blanca ni guchillos ni puñales (...) ni $<0>$ tras armas bedás».

10 Es evidente el alto nivel de variación en todo el mundo hispánico de las líquidas (/r/-/1/), las sibilantes, las implosivas intervocálicas y las consonantes implosivas, sobre todo [-s]. 
Esta consideración es válida, sobre todo, para los siglos XVIII y XIX, cuando se van difundiendo las normas académicas (Autoridades 1726, Epitome 1844; Decreto de Isabel II de 1844).

Un problema metodológico importante es la validación fonética de muchos de los rasgos gráficos que encontramos en las fuentes escritas, ya que puede tratarse de meras confusiones debidas a un dominio no completo del sistema de escritura. En relación con esto, podemos comparar nuestros testimonios con lo observado en la actualidad. Así, Paredes García (1999) señala usos en estudiantes madrileños de Secundaria que recuerdan a los recogidos en la documentación de nuestro corpus: confusión de palatales (ballador 'bañador', bizcollo 'bizcocho'), /f/ por / $\theta /$ (buzanda 'bufanda'), /k/ y /g/ (abrico 'abrigo'), simplificación de grupos consonánticos (acidente), la pronunciación interdental de /d/ implosiva (parez, narid), omisión de -/s/ (leone) y una llamativa neutralización de líquidas (saltenes, alcen, blazo, colifror). Este comportamiento transluce, por una parte, el habla cotidiana, pero, por otra, juega también un papel importante la impericia del scriptor, que afecta sobre todo a los casos de debilidad articulatoria, como en las implosivas.

Con una disposición separada de los fenómenos en documentación de la capital y de las zonas rurales, presentamos los rasgos significativos que nos permitirán aproximarnos a una interpretación de conjunto.

\subsection{El consonantismo en Madrid capital}

En primer lugar, consideramos el refuerzo articulatorio del diptongo /we/, que se forma con el fonema /g/-, del que tenemos manifestaciones en el siglo XVIII: güérfano: güerfanito $\left(281 / 003 / 0105,1741\right.$; güérfana $(282 / 001 / 218,1756)^{11}$. Otra variante aparece con la bilabial/b/-: buérfano $(282 / 002 / 0062,1812)$. Por otra parte, la secuencia/bwe/ y /bwa/ aparecen también con la grafía g-: güelto 'vuelto' $(371,1738)$; guardillas (282/001/0048, 1755).

En cuanto a las confusiones entre fonemas, destacamos el cambio de /f/ por / $/$ / (Celipa 'Felipa', 284/002/0171, 1839), en consonancia con una tendencia documentada

11 Güe- por hue- está atestiguado ya en el siglo xv, al menos; así, en CODEA se encuentra güeros (Salamanca, 1461) y güerto (Jaén, 1473). De igual modo encontramos agüelo/a en Zaragoza (1390) y Teruel (1460). En el s. XVI es un uso muy extendido, lo que explica la queja de Valdés en su Diálogo de la lengua: «Otra cosa observo; que si el vocablo comienza en $u$ vocal, y después de la $u$ se sigue $e$, yo pongo antes una $h$ antes que la $u$, y así digo huevo, huerto, huesso, etc. Hay algunos que ponen $g$ donde yo pongo $h$, y dizen güevo, güerto, güesso: a mi oféndeme el sonido y por esso tengo por mejor la $h »$. 
en la literatura costumbrista del siglo XIX ${ }^{12}$. En la actualidad, se ha apuntado este uso en hablantes poco formados de Castilla La Nueva (Moreno Fernández 2004: 216). Un fenómeno minoritario, pero que vale la pena mencionar, es la consonante antihiática registrada en un documento del corpus: criyare 'criare' $(281 / 003 / 0173,1741)$.

El fenómeno de la lenición se puede encontrar en diferentes ejemplos del corpus. Numerosos casos muestran el debilitamiento de la/d/ intervocálica en los siglos XVIII y XIX: hempedrao 'empedrado' (566, de 1716), o imposibilitaos (281/002, 0491, 1765); o, en -ido, á nacio 'ha nacido' (282/001/157, 1755). No falta en palabras semicultas pero generalizadas en el ámbito de la beneficencia, como ceula / zeula por cédula (351, 1715) y 356 (h. 1715); acristianao 'acristianado' (282/002/0529, 1817), Machao 'Machado' (571, 1823). La /-d/ final también se debilita en merzé (282/001/078, 1755), nesesidá 'necesidad' (281/003/099, 1741), solemnidá (282/001/208, 1756), berdá $(588,1821)$ y vondá $(656,1833)$. Esta inseguridad en la pronunciación se manifiesta en la sustitución de la grafía original por otras, como /s/: «De Madrís, 29 de noviembre de 1765 » $(281 / 002 / 0385,1765)$. No obstante, se produce un refuerzo articulatorio por medio de la interdental, que se encuentra en otros ejemplos como Madriz 'Madrid' (281/003/0068, 1741) y solenidaz (282/001/060, 1755). Otro fonema que se debilita es /g/ en posición interior de palabra en aosto 'agosto' (282/001/053, 1755).

En cuanto a la /s/ implosiva interior, a menudo parece aspirarse o perderse, a juzgar por critiana $(281 / 003 / 0151,1741)$ y «4 hijo sin más amparo que el del Altísimo» ['cuatro hijos'] (281/003/0083, 1741), seguramente favorecida por la fusión por fonética sintáctica con la /s/ de $\sin$. La pérdida de /s/ final queda apuntada por «cumple la niña tre años» $(282 / 001 / 162,1755)$. También se omite la grafía $s$, lo que quizá es un reflejo de la fonética, en las monjas trinitaria $(436,1811)$, y lo mismo en «Toda estas señales» (282/002/0092, 1816).

Uno de los fenómenos más llamativos en la documentación de la ciudad de Madrid de mano inhábil es la confusión de sibilantes alveolares y dentales (SánchezPrieto Borja y Vázquez Balonga 2015). Ya hay ejemplos en los siglos XVI y XVII: bautisado (33, 1594), mizericordia (46, 1595), sielo, resebilla, resibiré, (69, 1597), Gonsales (227 (s. f.); ce llama ${ }^{13}$ (109, 1599), llámace $(174,1609)$. Más frecuente es todavía en el siglo XVIII: saguán (382, 1738); distingsion, espesialidad, grasias (589,

12 En CORDE, se registra la forma Celipe en Marianela y el Doctor Centeno de Galdós y Tipos y paisajes de Pereda.

13 Sobre otros aspectos de la innovación en el consonantismo madrileño, véase Bustos Gisbert y Santiago (2002) y, para el castellano norteño frente a los usos meridionales, Pascual (1998). 
1741); conduscan (corregida en $z$ sobre $s)(281 / 003 / 092,1741)$, nasio 'nació' (403, 1741), nesesidad (281/003/0132, 1741), conosidos (282/001/0215, 1756); anocheser $(281 / 003 / 0198,1756)$. Por su alta frecuencia, hay que considerar el seseo en el verbo bautizar y sus variantes: bautisarme $(589,1741)$, bautisado $(281 / 003 / 0050,1741)$, bautisado (281/003/0202, 1742; 282/001/215, 1756; 282/001/139, 1755), bauptisso 'bautizó' (281/003/0226, 1742). Igualmente, se produce cambio de la grafía $s$ por $c / z$ para el fonema /s/: Zanches 'Sánchez' $(379,1738)$, nececidad (281/003/0045, 1741), cervir 'servir' $(281 / 003 / 0132,1741)$, «Maria Anastacia» $(281 / 003 / 0146,1741)^{14}$, ce llama 'se llama' (282/001/103, 1755), brocateles carmezies 'carmesíes' $(556,1712)$.

En el siglo XIX el índice de apariciones baja, pero todavían se ven algunos casos de confusión gráfica en la primera mitad: conosidos $(282 / 002 / 0192,1816)$, Secilia, sertificación, camiza, bambací 'bombasí' $(588,1821)$, dose, nasio (284/002/0044, 1839). Añadimos también casos de confusión de sibilantes en contexto implosivo, como en Isquierdo (282/002/0429, 1817), aunque este empleo tiene larga tradición ${ }^{15}$.

Otro grupo de consonantes que se ve afectado por la variación es el de las líquidas. Uno de los fenómenos más habituales es la metátesis, ya visible en la documentación de la Inclusa de los siglos XVI y XVII: probes (ALDICAM 56 / CODEA 1553, 1596) ${ }^{16}$, Grabiel (ALDICAM 106 / CODEA 1603, 1599), s.f. Flugencio (ALDICAM 134 / CODEA 1631, 1600), cofadria (ALDICAM 235/ CODEA 1504, 1603), prespectiva 'perspectiva' (ALDICAM 242 / CODEA 1511, 1653), Tribucio (ALDICAM 125 / CODEA 1622, 1599) (Sánchez-Prieto Borja y Flores Ramírez 2005). Hay que decir que formas como Grabiel y Tribucio están documentadas en obras cultas durante los Siglos de Oro ${ }^{17}$. La tendencia prosigue en el siglo XVIII en las notas de abandono del Refugio: «este niño nació día de santa Pretonila» 'Petronila'(ALDICAM 592, 1741), Grauiel 'Gabriel' (281/003/0150, 1741), probeza (281/003/0153, 1741). Tampoco deja de encontrarse en este fondo en la primera mitad del siglo XIX: Flugencia» (282/002/0617, 1817), Rodirgo 'Rodrigo' (282/002/0575, 1817), Anvorsio 'Ambrosio' (282/002/0286, 1817).

$14 \quad$ El hecho de tratarse de un nombre propio no muy introducido en la onomástica (v.i. 10.1.) tal vez favoreciera la indefinición gráfica.

15 En la base CORDE hay registros del s. XVII de isquierda: Luis Vélez de Guevara (h. 1613) y Antonio Enríquez (1644) y la Vida de Estebanillo González (1646).

16 En adelante, los documentos son referenciados con el número del corpus ALDICAM y, si también están disponibles en CODEA, con su cifra correspondiente. En este último es posible el acceso al documento en www.corpuscodea.es

17 Grabiel tiene numerosos ejemplos en documentos oficiales y obras de todo tipo, tanto en CORDE como en CODEA. Mientras, Tribucio aparece en un autor culto como Luis Cabrera de Córdoba (h. 1619). 
Junto a la metátesis, destaca la neutralización de líquidas, que da lugar tanto a rotacismo como a lambdacismo en posición final: «a nacido el dia de San Gir ['Gil'] a las tres y qualto ['cuarto']» $(282 / 002 / 0239,1816)$. Otros ejemplos son Guillelmo 'Guillermo' (282/002/0276, 1817), Tobal 'Tovar' (282/002/0388, 1817), percar 'percal', salga 'sarga' (282/002/0398, 1817), reselbandose $(282 / 002 / 0511,1817)$. Es un caso llamativo «queremos conosel la para gratifical a la qe la qrie» (282/002/0370, $1817)$, con $l$ que podría estar favorecida por asimilación entre líquidas en conosel la. Esta confusión también se da en /r/ intervocálica: Jabiela 'Javiera' (282/002/0497, $1817)^{18}$. Asimismo, se produce el trueque en los grupos de oclusiva y fricativa más líquida: «Maria Frora Costanza» 'Flora' (282/002/0397, 1817), esta quizá por contacto con la siguiente líquida /r/; En Crusa 'inclusa' (282/002/0504, 1817), rublica 'rúbrica' (284/002/0080, 1839). En ocasiones, la líquida se pierde, como en Abil (593, 1755), Alexanda 'Alejandra' (356, h. 1715), pobidencia 'providencia' (1755).

Por otra parte, los grupos consonánticos presentan simplificación en los documentos de los siglos XVI-XVII, sobre todo /kt/: eleto 'electo' (ALDICAM 244, 1662) y retor (ALDICAM 64 / CODEA 1561, 1597; 199, 1595; 164, 1605). Otros ejemplos posteriores son refitorio 'refectorio' (ALDICAM 426, 1679) ${ }^{19}$, ynacio 'Ignacio', hazidentada 'accidentada' (XXX), Portago 'Portazgo' (ALDICAM 569, 1803), amitir 'admitir' (ALDICAM 436, 1811), Madalena (ALDICAM 433, h. 1808), el siempre frecuente setiembre $(282 / 002 / 0429$ y 0542,1817$)$ o en el nombre ynacia 'Ignacia' $(284 / 002 / 0235,1839)$. En otros casos, los grupos cultos sufren un cambio de consonante. Esto se atestigua ya en el siglo XVII (reptor, 1605) y también en las dos centurias siguientes: reptor (354, 1715), solegnidad o solednidad (282/001/014, 1755), «Maria Conzencion de Ubeda» (281/003/0151, 1741), Magsimo 'Máximo' (281/003/193, 1741), solecnidad ${ }^{20}$ (ALDICAM 436, 1811), obtubre (282/002/0357, 1817), dinnen 'dignen' (590, 1831).

El yeísmo es otro fenómeno destacable, aunque está más limitado cronológicamente. Así, se registran ejemplos únicamente en el siglo XIX: lla (434, h. 1810), se yama (282/002/0327, 1817), yamar, apeyido, viya 'Villa', como apellido (282/002/0353, $1817)$, aller 'ayer' $(282 / 002 / 0411,1817)$. Además de la grafía $y$ por $l l$, apuntamos formas ultracorrectas, indicadoras de la indistinción, como Balleta $(282 / 002 / 0588,1817)$ y valleta 'bayeta' $(284 / 002 / 0044,1839)$. En la literatura es difícil ver testimonios del

18 Podría ser esta forma influida por Javiel $(282 / 002 / 0561,1817)$.

19 No obstante, refitor y refitorio fueron formas habituales desde el castellano medieval, según atestigua el CORDE.

20 La alta concentración de ejemplos de solemnidad se debe a su pertenencia a la beneficencia, ya que abunda la fórmula pobre de solemnidad. 
yeísmo en este período de tiempo, pero hay indicios de que estaba presente al menos desde finales del siglo $\mathrm{XIX}^{21}$, y que la difusión fue un cambio desde abajo (Molina Martos 2013). Ya que resulta imposible saber la procedencia foránea de los scriptores de estos textos, podemos, al menos, confirmar que, a la luz de los documentos, el yeísmo se encontraba en hablantes de la capital desde la primera mitad de la centuria.

\subsection{Consonantismo en la documentación de ámbito rural}

Un fenómeno que caracteriza hoy las hablas rurales de gran parte del dominio hispánico es el refuerzo del diptongo /wé/, que recibe un suplemento consonántico inicial de carácter velar, acústicamente próximo al primer elemento de este diptongo. Ha de notarse que la percepción diferenciada de estas dos posibilidades articulatorias no es absoluta, por lo que puede decirse que solo las formas más enfáticas o marcadas de refuerzo se perciben con nitidez. En ALDICAM hemos encontrado «las dichas huertas y guertos» (309, Arganda del Rey, ca. 1605); «cada guerta o guerto» (310, Arganda del Rey, 1605); guerto (ALDICAM 270/ CODEA 1788, Daganzo de Arriba, 1788; ALDICAM 272 / CODEA 1790, Daganzo de Arriba, 1588; ALDICAM 292 / CODEA 1811, Daganzo de Arriba, 1591); guerta (701, Getafe, 1568; 486, Cadalso de los Vidrios, 1664). El mismo fenómeno, pero en posición interior de palabra, se aprecia en alcaguetes (475, El Escorial, 1771) y «tocino salado y desguesado» (521, Hoyo de Manzanares, 1706).

La variante tobajas (487, Alcorcón, 1590) muestra su labial fricativa conservada, como alternativa a la moderna toalla, de la que se diferencia también por la palatal ${ }^{22}$. En la ciudad de Madrid encontramos también toalla en un inventario de bienes de 1653 (CODEA 1511 / ALDICAM 242), y en las fuentes lexicográficas aparece ya en el diccionario de Casas de 1570 (NTLLE, s.v. ${ }^{23}$. Ambas variantes coexistieron largo tiempo, pues en CODEA se documenta tobaja desde 1237 (Toledo) hasta 1643 (Baterno, Badajoz).

La confusión fonológica de $/ \mathrm{b} / \mathrm{y} / \beta /$ es un fenómeno que remonta probablemente al s. Xv, pero queda frecuentemente enmascarado por la práctica, bastante regular, de los escribas. En los documentos madrileños de ámbito rural encontramos, p. ej.,

$21 \quad$ En Fortunata y Jacinta se menciona «Daba a la elle el tono arrastrado que la gente baja da a la $y$ consonante», un uso, por lo tanto, asociado a la clase popular (López 1978).

22 Hay que señalar que toballa está recogida en el DLE como voz desusada. En el ALeCMan (mapa Fon. 109, «Toalla») la forma con la labial intervocálica se registra en puntos del oeste de Guadalajara, Toledo y Ciudad Real.

23 En el CORDE se encuentra ya en las Cartas y relaciones de Hernán Cortés (1519-1526). 
estaba en 1541 (ALDICAM 16 / CODEA 1480, Alcalá de Henares, 1541), o daba (ALDICAM 307 / CODEA 1828 / Arganda del Rey, 1581), en lugar de la grafía $v$ propia del contexto intervocálico para -B- etimológica del paradigma del imperfecto. La variación gráfica saue / sabe (265, Daganzo de Arriba, 1593) indica también confusión entre labiales, pues la grafía tradicional era $b$ (lat. SAPERE).

El mismo planteamiento metodológico es válido para la confusión de sibilantes, pues ha de suponerse que la igualación fonológica precedió a la gráfica, al menos a la generalización de esta última. Los escribanos profesionales mantuvieron, aunque no $\sin$ excepciones, las parejas $c, c ̧ / z$ y $x / g, j$ hasta el último tercio del s. XVI, mientras que $s$ invadió desde el $\mathrm{s}$. XIV el espacio de $s s$, en gran parte por la extensión de la $s$ sigmática en las escrituras cursivas. Hay, sin embargo, quien ha retrasado la igualación entre sibilantes sordas y sonoras hasta finales del s. XVI (Blanco 2007). Los documentos de diferentes localidades madrileñas alternan en la segunda mitad del XVI las grafías de las antiguas sibilantes dentales y, así, vemos hacer (CODEA 1424, Alcalá de Henares, 1521), decir (ALDICAM 247 / CODEA 1745, Alcalá de Henares, 1565), hacienda (ALDICAM 248 /CODEA 1746, Alcalá de Henares, 1565); haçer (619, San Lorenzo de El Escorial, 1569), hiço, hiçieren, diçe (ALDICAM 262 / CODEA 1780, Daganzo de Arriba, 1587); diçen, hiço (ALDICAM 471, El Escorial, 1587); judiçial (ALDICAM 470, El Escorial, 1587); deçir (ALDICAM 265 / CODEA 1793, Daganzo de Arriba, 1593). De las sibilantes alveolares no merece la pena recoger los innumerables testimonios de $s$ por ss (fuese), pero sí ss por s: cossa (ALDICAM 620, San Lorenzo de El Escorial, 1596; ALDICAM 3, Arroyomolinos, 1650). En cuanto a las grafías de las antiguas prepalatales, llama la atención la extensión de $x$ por $g$-j, como en helexir 'elegir' (617, San Lorenzo de El Escorial, 1563), escoxido, maxestad, (ALDICAM 619, San Lorenzo de El Escorial, 1569); mexor, destaxero y, de manera contraria, dige (ALDICAM 470, El Escorial, 1587). También en el último tercio del s. XVI se encuadra la alternancia gráfica para la misma palabra en un mismo documento: «tinaxa [...] tinaja» (ALDICAM 488, Alcorcón, 1575).

Consignamos aquí una serie de confusiones que estimamos solo gráficas, pero que, por su recurrencia, dan una idea del grado de dominio de las convenciones de la escritura por parte de los escriptores locales, normalmente particulares, o miembros de la administración que no son profesionales de la pluma: guzgo 'juzgo' (331, Santa María de la Alameda, 1695), «tres enzinas que ay guntas» 'juntas'; «con el arroyo de la Sacera azi'abago» 'abajo' (646, Colmenar Viejo, 1775); «los guéneros muy malos [...] Jeneros» (696, El Escorial, 1770); «armas (...) ni cortas ni blancas [...] ni regones» 'rejones' (711, Garganta de los Montes, 1808); «ni larja ni corta» 'larga' (712, La Hiruela, 1808); «Guan» 'Juan' (Montejo de la Sierra, 1857); «page» 'pague', 
«consegir» 'conseguir' (Montejo de la Sierra, 1858); «Un canastillo viego» (Montejo de la Sierra, 1861). Es poco probable que los casos anteriores indiquen otra cosa que cierta impericia de quienes escriben, pero no dejan de interesar, a veces, por su posible motivación fonética, bien que ocasional, como resultado de procesos de asimilación; así podría explicarse guzgo por 'juzgo'.

Una motivación diferente parece tener la grafía compleja en «un portal donde se recoxga el ladrillo de las aguas»' 'recoja' (619, San Lorenzo de El Escorial, 1569), pues tal vez pueda explicarse la variante por cambio en la morfología verbal. En efecto, se ha señalado para algunas hablas centrales, como la variedad de Cuenca, el indicativo en -go y subjuntivo en - ga para diversos verbos: cuezgo 'cuezo', parezgo 'parezco'24.

Resulta extraña la consonante inicial de juzguillo (603, Arganda del Rey, 1775), forma que en el contexto tiene el sentido de 'perro pequeño' («cazando con dos galgos y un podenco o juzguillo»). Es posible que esta voz, de la que no hemos encontrado otras documentaciones, se haya de poner en relación con gozque 'perro pequeño', de origen onomatopéyico (DCECH, sv. gozque; cf. port. goso, cat. gos). La forma documentada en Arganda podría ser una mala grafía por guzguillo, pero sin descartar la validación fonética como $/ \mathrm{x} / \mathrm{de}$ su - $g$ inicial.

Hay confusión entre /k/ y /g/ en posición inicial en garuchas 'carruchas' (618, San Lorenzo de El Escorial, 1567); esta variante estuvo muy extendida en diversos ámbitos geográficos. Ya Palmireno (1560) señaló carrucha como solución aragonesa, frente a la supuestamente toledana polea; sin embargo, garrucha está atestiguada en Toledo hacia 160025 (González Ollé 1995: 303-329). Esta forma es recogida en la lexicografía española desde el Vocabulario español-latino de Nebrija de 1495 (NTLLE), y aun puede considerarse más frecuente que carrucha hasta el s. XVIII, centuria en la que ambas igualan sus frecuencias según los datos del CORDE. Según ALeCMan (García Mouton y Moreno Fernández 2003), en Guadalajara y la zona norte de Toledo, limítrofe con Madrid, domina hoy en día garrucha frente a carrucha, que se ve más al sur.

La variante guchillo («ni guchillos ni puñales» 'cuchillos'; 712, La Hiruela, 1808) se recoge por primera vez en el Diccionario de Salvá (1846), y por última en Zerolo

24 En el CORDE se documenta cuezgo en el Marqués de Santillana: «Espera muerto que verças te cuezgo» (Refranes que dicen las viejas tras el fuego, 1454). La forma cuezga es más frecuente y se encuentra en la Obra de agricultura de Alonso de Herrera (1513) y en otros tratados del siglo XVI.

25 «Item que en cada una d'estas casas esté puesto con sus garruchas una romana sutil e fiel en que se pesen todos los costales e sacas de pan que llevaren a moler» (Archivo Municipal de Toledo, Cajón 3, legajo 3, n 15, s.a.).. 
$(1895)^{26}$. A principios del siglo Xx debía de ser guchillo ya una variante vulgar. Otros casos de $g$ por $/ \mathrm{k} /$ parecen tener carácter excepcional, y son atribuibles seguramente solo a lapsus calami, pero no dejamos de consignarlos por un hipotético carácter siquiera idiolectal: «Eh, gue digo algo», 'que' (475, El Escorial, h. 1770).

Muestra sorda por la sonora «una palancana» (727, Montejo de la Sierra, 1894); la variante está en el diccionario de Terreros y Pando (1788, NTLLE), y en el CORDE desde 1681, pero es minoritaria respecto a la solución con $g$, por lo que la solución documentada en Montejo de la Sierra, en una fecha tan tardía como 1894, puede considerarse adscrita a los registros más populares. Cofaina por jofaina parecería mero lapsus ocasional si no se documentara dos veces en el mismo documento: «dos cofainas», «un trespiés para la cofaina» (480, Aranjuez, 1805). Resulta curioso comprobar que la única documentación en CORDE es del madrileño Mesonero Romanos ${ }^{27}$.

Un fenómeno extendido es la igualación $/ \mathrm{b} /-\mathrm{g} /$, favorecida por el contacto con la vocal velar /u/: Abujetas 'Agujetas' (709, Torrelaguna, 1800), Avujetas (Pinilla de Buitrago, 16,13, 1818); estos usos eran corrientes hasta hace poco, y aún hoy, en el mundo rural y en las variantes populares del español, dentro de una haz de procesos que incluyen la pérdida del elemento consonántico (cf. agujero/abujero/ aujero/ujero $)^{28}$. En el CORDE, «seis abujetas de colonia parda» (1655). En el ADiM se documenta en encuestas recientes en la Sierra Norte: abuja para 'aguja' en Buitrago del Lozoya, Lozoya y Mangirón. En Alvar Ezquerra (2011), bujero en Bustarviejo, bujerito en Titulcia; mientras que en Hoyo de Manzanares (NO) y en localidades del NE (Torrelaguna, Algete, Talamanca), hay abuzar por aguzar.

La pérdida de la labial fricativa intervocálica está acreditada por tauretes 'taburetes' (761, Montejo de la Sierra, 1856). Esta variante la recoge el $D L E$ con la marca geográfica Nic. En el CORDE se encuentra una sola vez en un autor peruano, López Abújar, en 1928, pero tauretes aparece en dos inventarios de bienes de Toledo de 1619 y 1626, así como de Arganda del Rey en 1688 (Vázquez Balonga 2015: 447). Las fuentes lexicográficas también la presentan: Franciosini (1620) y Autoridades (1739) (NTLEE). La voz es un galicismo, pues procede de fr. tabouret, variante del antiguo francés tabour 'tambor', por comparación con la forma ( $D C E C H$, s.v. tambor); debió de entrar en español en el s. XVI, y lógicamente, se pronunciaría con una labial fricativa, lo que explica su pérdida.

26 En el CORDE, casi todas las apariciones de guchillo son del aragonés Fernández de Heredia (s. XIV) y del manchego Juan Bautista de la Concepción (ss. XVI-XVII).

27 «Pedimos agua para lavarnos, nos trajeron una cofaina sucia y ordinaria» (Escenas Matritenses de 1832).

28 En Fortunata y Jacinta, de Galdós (1885-1886), ujeritos por 'agujeritos'. 
Un posible debilitamiento de /g/ inicial muestra «un par de huantes» (663, El Escorial, 1688). No hemos encontrado esta variante en otras fuentes, por lo que la consideramos un hápax, que, si acaso, podría mostrar cierto debilitamiento de la oclusiva sonora, que pasaría a pronunciarse fricativa favorecida por el contexto intervocálico por fonética sintáctica.

En posición intervocálica, la /g/ se pierde en «instrumento contundente y maullante» (699, Robledo de Chavela, 1688). Hay que notar que el sintagma «instrumento magullante» está documentado ${ }^{29}$, por lo que no cabe duda sobre la interpretación de la forma atestiguada en Robledo de Chavela. No hemos encontrado maullante en las fuentes consultadas. Para el $D L E$, el étimo es MAGULARE, quizá con cruce con abollar.

La misma pérdida consonántica muestra la voz ceajo (727, Montejo de la Sierra, 1894), si la consideramos procedente de cegajo. En las fuentes lexicográficas se documenta solo desde el Diccionario de Autoridades de 1729 (NTLLE), donde es «chivo o cordero que no llega a primal», y allí tiene la marca geográfica "Aragón». Según el $D C E C H$, es variante de segallo (s.v.), aunque se ha de precisar que la forma castellana, con $/ \mathrm{x} / \mathrm{y}$, presumiblemente, en lo antiguo con prepalatal sonora, no puede provenir de una voz con palatal lateral, sino de un grupo de LY. El DCECH emparenta segallo ('animal cabrío en el segundo año de su vida') con el vasco segail/sekail y catalán secall. La primera documentación que ofrece es de un inventario aragonés de 1405, al parecer en la forma segallo. Como Borao (en DCECH) registra cegallo, hay variantes valencianas de tipo segai-segaia, y en Andalucía, así como en el diccionario de Terreros y Pando (1786, NTLLE), se encuentra cegajo, la forma documentada en la localidad madrileña de Montejo de la Sierra es, sin duda, una evolución ulterior a partir de esta última forma, que consiste en la pérdida de /g/ intervocálica.

Un fenómeno muy extendido en las formas rurales y populares del castellano es la confusión entre bilabial/b/ por velar/g/: «frígola» 'frívola' (536, Camarma de Esteruelas, 1754), en una declaración judicial de un querellante, por lo que no es seguro si tal forma ha de adscribirse a la manera de hablar del que denuncia o, lo que parece más probable, al escribano que recoge la declaración y, eventualmente, modifica los usos de la declaración oral: «y absorto de verle en tal paraje y a mi muger en la calle, dio por escusa frígola estaba leyendo las rotulatas de algunas estampas que tengo en mi cuarto». La confusión de las mismas consonantes fue muy frecuente en «un jugón» 'jubón' (761, Montejo de la Sierra, 1856). En CODEA se encuentra en Villar de Pedroso (Cáceres) en 1684 (en el CORDE, en 1763).

$29 \quad$ Martín Martínez, Examen nuevo de cirugía moderna, Valencia, Ildefonso Mompié, 1830, p. 120. 
Las sonoras /g/-/d/ se confunde en «quatro Vadages» (706, Buitrago del Lozoya, 1804), si se trata de una variante de 'bagajes', como parece deducirse del contexto: «ochenta reales vellón en esta forma, veinte que se les dieron para alimentos en la noche que llegó, doze por cuatro vadages menos de Villavieja y los cuarenta y ocho restantes por seis xornales que se emplearon en su conduzión». En la base CORDE hay un solo caso, de Galdós (Misericordia): «Y en Valencia encontrastes a la Nicolasa, con quien veniste por badajes, que vos daban los aiuntamientos».

En cambio, sí es corriente la palatalización de la nasal en «cañutillo de plata» (663, El Escorial, 1688), hecho del todo lógico si se parte de caña, voz de la que se habría formado canuto por derivación. El $D L E$ y el $D C E C H$ proponen una etimología mozárabe qannût, aunque lo más cierto es partir de lat. CANNA, a la que se añade el sufijo -uto, nada raro, con su -t-, en español. La variante con nasal palatal está muy extendida hoy en Aragón, La Mancha y otras regiones, y está recogida en toda la lexicografía española desde el diccionario de Nebrija de 1495 (NTLLE). La variación entre las alveolares nasales palatal y no palatal presenta numerosos perfiles dialectales, cronológicos, sociolingüísticos e, incluso, idiolectales, sobre todo por lo que concierne a la posición incial (cf. ñuca 'nuca'), pero, en el caso que nos ocupa, la asociación etimológica con caña explica del todo la presencia de la palatal. Hay numerosas documentaciones en CORDE desde el siglo XV, entre las que cabe destacar la Agricultura de Herrera (1513): «un cañuto gordo de caña».

La metátesis de líquidas es un fenómeno que recorre toda la historia del español, pero la fijación progresiva de las formas canónicas, no siempre etimológicas, relegó las variantes al ámbito del vulgarismo, aunque esto es válido solamente desde avanzado el s. XVIII: «razón de las enzinas infutríferas» 'infructíferas' (646, Colmenar Viejo, $1775)^{30}$. No es raro deshacer el grupo de «muta cum líquida»: «día del patorzinio de Nuestra Señora» (331, Santa María de la Alameda, 1695). La anticipación de la líquida agrupada se observa en «plaça plública» (491, Valdemoro, 1674). La /r/ implosiva reverbera en pircardías, tarberna (475, El Escorial, ca. 1770). En peticiones de juicio verbal, por impagos casi siempre, se lee «juicio vrebal» (Montejo de la Sierra, 1858). La secuencia /rl/ conoce metátesis en «una manta de arlotas» 'alrotas' (729, Montejo de la Sierra, 1894); ambas formas están recogidas en el $D L E$. La /1/ implosiva se cambia en /r/, además de darse dilación de la misma a la sílaba siguiente: «una cuartilla de alberjas», forma generalizada para 'arvejas'<ERVILIA) (727, Montejo de la Sierra, 1894). Parece hápax Marid 'Madrid' (521, Hoyo de Manzanares, 1706), con pérdida de la líquida en grupo /dr/.

30 En el margen, posiblemente de otra mano: «Son todas las enzinas infructiferas 61». 
La neutralización de alveolares /n/-/1/ es común en toda la historia del español. La variante Menchor (487, Alcorcón, 1590; 14, Hoyo de Manzanares, 1733), por Melchor, puede oírse todavía en el habla popular de zonas rurales. Pero son las líquidas /1/ y /r/ las más fácilmente sometidas a procesos de asimilación y disimilación, debido a su proximidad articulatoria ${ }^{31}$. La asimilación se muestra en «el artar mayor» (475, El Escorial, h. 1770), «a juicio verbar» 'verbal' (764, Buitrago del Lozoya, 1865). El cambio de /r/ en /1/, espontáneo o influido por otra líquida, se aprecia en huelfana (19, 3, Buitrago del Lozoya, 1830), cualtel 'cuartel' (662, El Escorial, 1688), mercadel 'mercader' (664, El Escorial, 1688). Resulta difícil acotar geográficamente el fenómeno, ya que tradicionalmente suele considerarse un meridionalismo, pero lo cierto es que está muy extendido en otras regiones. Sin embargo, para la terminación de infinitivo, en el ADiM (García Mouton y Molina Martos 2015), solo en el Cenicientos, en el SO de la Comunidad, se encuentra/xugál/, mientras que en todos los demás puntos encuestados la respuesta en /xugár/. Por otra parte, en algunas localidades de la región se produce neutralización con rotacismo o lateralización ${ }^{32}$.

En posición interior es forma documentada desde la Edad Media zelebro 'cerebro' (699, Robledo de Chavela, 1688). Se encuentra ya en la General estoria, Poridat de poridades y otros textos del s. XIII, centuria en la que alternaba con la etimológica cerebro (lat. CEREBRUM).

La pérdida de / $\mathrm{r}$ / agrupada con consonante se aprecia en «un caldero de cove» 'cobre' (Montejo de la Sierra, 1861), tal vez mera errata o descuido gráfico, pero que ha de tenerse en cuenta por lo que pudiera indicar sobre la pronunciación de los grupos de oclusiva con líquida. No es seguro que en «un rastillo de rastillar» (761, Montejo de la Sierra, 1893) nos encontremos ante pérdida de /r/, pues bien podría ser rastillo la forma mantenida desde un étimo RASTELLUS, como señala el DLE, y que rastrillo represente, en realidad, una forma epentética, tal vez por cruce con rastro $^{33}$.

31 La variación entre /r/ y /1/ implosivas fue frecuente sobre todo en ciertas palabras, como armario/ almario, según recoge Covarrubias (1611) (s.v. almario): «El al no es arábigo, sino que la $\mathrm{R}$ y la L se comutan [...], pero otras vezes la comutan en L, como calne por carne, pelo por perro; y assí esta dicción almario es lo mesmo que armario» (NTLLE).

32 Se señala rotacismo en Mangirón (Norte) y Meco (Este) y lateralización en Buitrago, El Boalo (Norte), Cenicientos (Suroeste) y Carabaña (Este), aunque sobre todo en encuestados hombres, mientas que en las mujeres hay más neutralización en el sur (2017:31). De todas formas, en el nivel informal, parece que se neutraliza con frecuencia /r/ y /1/ en la terminación de infinitivo en numerosos hablantes madrileños (v.i. 6.).

33 Un caso parecido podría ser el de rastrojo a partir de un RESTUCULO, quizá por cruce con rastro. Por lo demás, la secuencia «un rastillo de rastillar» está, por ejemplo, en el Inventario por secuestro de bienes moriscos del reino de Granada, de 1562 (en CORDE). 
La pérdida de la /r/ final es un fenómeno que suele atribuirse a las hablas meridionales (Álvarez Martínez 2004: 178), pero en nuestro corpus se atestigua en el oeste de la Comunidad de Madrid: «el panadero no puede entra en su tierra» (475, El Escorial, ca. 1770). Este fenómeno sigue documentado en encuestas recientes en la zona nordeste de la Comunidad de Madrid (Ruiz Martínez 2000: 240).

Un rasgo de amplia extensión en el castellano conversacional de hoy, con desigual presencia en los distintos niveles sociolingüísticos de las diferentes zonas del español peninsular, es la pérdida de la /d/ intervocálica (Molina Martos 2001). Es de suponer, y así lo atestigua el $A L P I$, que ni siquiera en la primera mitad del s. Xx alcanzaba la extensión que tiene hoy fuera del registro formal. Sin embargo, en los siglos XVIII y XIX tenemos varios testimonios altamente significativos en poblaciones serranas de la Comunidad de Madrid: «los reitos» 'réditos' (14, Hoyo de Manzanares, 1733), «armas bedas» 'vedadas' (712, La Hiruela, 1808), «dicha deuda procede de un carro que ice para la indica Brijeda», por 'indicada' (Buitrago del Lozoya, 16,4, 1884), «de estao casado» (Montejo de la Sierra, 1857), «le é pedio», «no é podio» (Montejo de la Sierra, 1858). Más dudoso resulta «color palio» 'pálido' (Buitrago del Lozoya, 20/13, 1823), pues cuando el resultado es un diptongo no parece probable que se pierda $/ \mathrm{d} /$.

El debilitamiento y eventual pérdida de la /d/ en posición intervocálica tiene paralelo en la implosiva final de palabra, como se aprecia en «la metá» 'mitad' (14, Hoyo de Manzanares, 1733), «paré curiosa» (Buitrago del Lozoya 16,12, h. 1820). Esta última palabra conoce la interdentalización de su -/d/: parez (Buitrago del Lozoya 16,12, h. 1820). También resulta relevante la documentación del mismo fenómeno en localidades del sur de Madrid, en un caso, en fecha temprana, si nuestra lectura es correcta: «huiz de pleitos y litigios» (600, Parla, 1817). La forma ultracorrecta «robusted» 'robustez' (Buitrago del Lozoya, 20/13, 1823) parece corroborar que la /d/ final se pronunciaba de manera corriente como interdental o, al menos, que no era rara. También podía afectar esta interdentalización a otras implosivas: «la veniznidad de el ayuntamiento» (615, Colmenar Viejo, ca. 1775); el fenómeno no ha de sorprender, habida cuenta de la indefinición articulatoria que afecta a muchas de estas consonantes en esta posición.

Más rara resulta la confusión entre /d/ y /b/ intervocálicas en azabilla» (761, Montejo de la Sierra, 1894), que suponemos variante de azadilla ${ }^{34}$. Por último, notaremos el debilitamiento de $d$ - explosiva en «de icho» 'de dicho' (Montejo de la Sierra,

34 Sin descartar la equivalencia acústica en ese contexto, tal vez pueda apuntarse el cruce con escabilla (documentado en Ciudad Real), derivado posverbal de escavillar, verbo este recogido por el DLE, con la marca geográfica «Albacete y Andalucía», como variante de escavar. 
1857) y «un guato de estete» (729, Montejo de la Sierra, 1894). En este segundo caso, el motivo de la pérdida de /d/ parece la variación entre es- y des- como prefijos negativos, mientras que el icho por dicho puede tener una motivación fonética, máxime al estar su/d/ inicial en contexto intervocálico por fonética sintáctica.

La omisión de /n/ ante /t/ y otras consonantes tiene carácter ocasional, y así encontramos, en el mismo documento «treita» 'treinta'; «Sachez» 'Sánchez' (14, Hoyo de Manzanares, 1733). Tampoco dejamos de consignar la variante dinguna, por ninguna, a sabiendas de que el fenómeno tiene implicaciones morfológicas y no meramente fonéticas: «persona dinguna que dijese nada» (745, Somosierra, 1828) ${ }^{35}$.

En toda la historia del español, fuera de la pronunciación cuidada o de la lectura, el grupo /ns/ se simplifica en /s/»: «para que coste» (742, Piñuécar-Gandullas, 1800); «costar ... constando» (734, Alcalá de Henares, 1847). Una /n/ epentética se observa, quizá por cruce con santo, en santisfazion 'satisfacción' (3, Arroyomolinos, 1650). Las implosivas se reducen en escritos de diversos grados de formalidad en los llamados grupos cultos, especialmente en /kt/ (efeto 'efecto', otubre 'octubre', 620, San Lorenzo de El Escorial, 1596); ha de considerarse, sin embargo, que con el tiempo van adquiriendo una connotación vulgar en la escritura, pero este fenómeno no es claro que estuviera consolidado hasta el s. XIX: «Rectora [...] Retora» (733, Alcalá de Henares, 1856), «y que no he podido acer efetibo» (764, Buitrago del Lozoya, 1865), «efetiba» (773, Montejo de la Sierra, 1872).

El debilitamiento de las implosivas se refleja en el cambio entre las grafias de estas consonantes, sin que quepa deducir la pronunciación a partir de la escritura, sino que más bien hay que pensar en neutralización de implosivas debido a su escasa perceptibilidad. Ha de tenerse en cuenta que se trata de palabras de ámbito culto las más de las veces, por lo que algunas no son frecuentes en la lengua hablada: avbirtieron (611, Arganda del Rey, 1798), «que previos los informes que guste adquirir de mi adtitud» (5, Villa del Prado, 1844), eçebto 'excepto' (577, Chinchón, 1532), subcesibo (735, Alcalá de Henares, 1834; 746, Buitrago del Lozoya, 1834), «ansí como conzejo e a liz del azestamos en nuestro favor esta escriptura» 'aceptamos' (680, Chinchón, 1577), pracmaticas 'pragmáticas' (710, Buitrago del Lozoya, 1808), adtualidad (751, Alcalá de Henares, 1854), «se dicne concederle», benicno (751, Alcalá de Henares, 1854), casos estos dos en los que no puede descartarse que transluzcan una pronunciación interdental. Una implosiva de timbre indefinido puede interpretarse como mala pronunciación de /s/, lo que explica grafías como «respestiba» (Buitrago del

35 En CORDE se encuentra en un texto que recrea el habla de Murcia (que dinguna presona la melque) (Javier Fuentes y Ponte, Murcia que se fue, 1872). 
Lozoya, 19/13, 1831). Más extraña resulta la forma oupto por 'apto': «se encuentra oupto para su desenpeño» (747, Alcalá de Henares, 1862).

Hay simplificación del grupo /mb/ en zabullo, zabullir (661, El Escorial, 1688), pero, mientras que en los procesos conocidos en la historia del español desde la Edad Media es la nasal el único fonema que resta del grupo $/ \mathrm{mb} /$ (lomo $<$ LUMBU), aquí es este el que se pierde. Sin duda, ha de pensarse en la morfología verbal, pues $z a$ - es componente inicial de algunos verbos (zaherir, zahondar); de hecho, uno de los resultados de sub- es precisamente este sufijo (García Hernández 2000).

Merece atención particular la variación gráfica entre $x, k s$, cs y otras secuencias, pues muestran, por una parte, la tendencia a la simplificación del grupo $/ \mathrm{ks} / \mathrm{y}$, por otra, los problemas que tienen muchos scriptores para la identificación correcta de las palabras en las que la tradición gráfica, y luego la RAE, fijó el empleo de $x$ : exsaminen (470, El Escorial, 1587), «se edsaminó» (3, Arroyomolinos, 1650), ecsamenes («Francsico Rodrigo, natural de Madrid») (8, Cercedilla, 1844), esigirle, esponente (8, Cercedilla, 1844), «prógsimo» (521, Hoyo de Manzanares, 1706), afexto 'afecto'(331, Santa María de la Alameda, 1695), «con la mayor saxtitud» (Buitrago del Lozoya 16,11, 1819), protextas 'protestas' (607, Arganda del Rey, 1791).

Un fenómeno que suele considerarse de origen meridional, además de extendido tardíamente, es el debilitamiento de $-/ \mathrm{s} /$ final $^{36}$. Sin que unos pocos casos permitan concluir su generalización temprana en las hablas madrileñas, sí cabe consignarlos por si pudieran ser indicio del fenómeno en localidades madrileñas, incluso las situadas al norte, en el s. XIX: «fuimo la orilla del río arriba» (3, Arroyomolinos, 1650), «Dos frascos pequeñillo» (Montejo de la Sierra, 1861), «medios amistoso» (773, Montejo de la Sierra, 1872).

En cuanto a las sibilantes alveolares, el cambio en / $/$ / por asimilación se muestra en zauzes 'sauces' (662, El Escorial, 1688) y «pared zenzilla» 'sencilla' (521, Hoyo de Manzanares, 1706). Esta última forma parece haber tenido cierta extensión, y así la encontramos ya en los romances de Góngora (en CORDE). Un hipotético seseo parecen translucir las formas casuelas, limpiesa, y, en posición implosiva, almires (Buitrago del Lozoya 16/15, 1816); hay que notar que el documento no corresponde a un vecino de los pueblos de la Sierra, sino a «Carlos Pollastrini», probablemente italiano. En un escrito de Alcalá de Henares (748, Alcalá de Henares, 1822) se lee complaserlo; está firmado por «M. Elena O'Neill», a todas luces foránea. Menor valor tiene la /s/ final en Gusman (747, Alcalá de Henares, 1862), por tratarse de la implosiva, posición en la que la variación en nombres propios fue frecuente.

36 Pueden consultarse al respecto los trabajos clásicos de Alonso (1962), Navarro Tomás (1975) y Alvar (1955). 
Por último, el empleo de $y$ por $l l$ podría apuntar a yeísmo: «en atención de ayarse vacante la plaza de sereno» (747, Alcalá de Henares, 1862). Es excepcional, en contraste con los testimonios en documentos decimonónicos de la ciudad de Madrid (v.s. 4.1.).

\section{INTERPRETACIÓN DE LOS DATOS}

Muchos de estos fenómenos son reflejados en los personajes madrileños de clase humilde en la obra literaria de Benito Pérez Galdós. Algunos ejemplos son el debilitamiento de - $d$ - intervocálica, sobre todo en casos de participios y adjetivos acabados en -ado/a: ensalzaos, honrás 'honradas' (Misericordia), sellaito 'selladito', alilao 'alelado' (Fortunata y Jacinta). También la pérdida de - $d$ final (senetú, 'senectud', Misericordia). Otros, menos conocidos, se reflejan también, como la metátesis de líquidas (presona, en Fortunata y Jacinta), el refuerzo de -wue- con /b/ (buérfanos, en Fortunata y Jacinta), confusión de /b/ y /g/ (rigolución, golver), y entre /f/ y /0/ (Celiplinas 'Filipinas', en Misericordia, v.s. 4.1., Celipa). Esto prueba que los documentos reflejan tendencias fónicas relativas al consonantismo notablemente extendidas, al menos entre las clases populares, y no solo usos esporádicos. Se refuerza así la presunción de veracidad de los testimonios gráficos encontrados en los archivos.

En cualquier caso, si las hablas capitalinas tienen una mayor complejidad social, quizá hay mayor dispersión en las rurales, que abarcan, lógicamente, todo el espacio de la CM. Contrastan, aun así, con la mayor riqueza documental de la ciudad, que, gracias a los fondos de instituciones benéficas, por la vía de las peticiones, nos ofrece escritos de manos inhábiles que no tienen paralelo en los pueblos, en los que, con excepciones, eso sí, de extraordinario valor, como los pasquines de El Escorial, suelen tomar la pluma escribanos más o menos profesionales, aunque en el siglo XIX se multiplican en documentos municipales las manos poco habituadas a escribir (por ejemplo, los «fieles de fechos» y alcaldes pedáneos de aldeas). Muchos rasgos de los pueblos tienen carácter ocasional, más ligados a impericia gráfica que a características fonéticas del habla de allí. Lo que sí queda probado es que la diversificación sociolingüística en el mundo rural es notable.

En cuanto a la cronología de los cambios fonéticos, el consonantismo madrileño tiene carácter innovador, pues la confusión entre las grafías de sordas y sonoras se encuentra de manera recurrente desde mediados del s. XVI ( $c$ por $z, x$ por $g-j, \mathrm{y}$, por descontado, ss por $s$ ). Ello se observa en la ciudad de Madrid y en zonas rurales. El hipotético seseo, por su parte, se documenta también esporádicamente en el siglo XVI, mientras que el yeísmo es mucho más tardío. 
Quizá, el fenómeno más llamativo es el seseo en la ciudad de Madrid (Vázquez Balonga y Sánchez-Prieto Borja 2015), que suponemos de origen no foráneo, al menos no en todos los casos, habida cuenta de su documentación frecuente en los ss. XVIII-XIX por empleados de la Hermandad del Refugio, que escriben, p. ej., saguán de manera casi sistemática. En cambio, otros casos de posible confusión, como zencillo 'sencillo' que encontramos en documentos emitidos municipios de la CM son muestra de asimilación consonántica, pero no propiamente de seseo. Lo que sí parece claro es que se trata de un fenómeno urbano, pues no hemos encontrado indicios del mismo en otras localidades.

También parece fenómeno difundido inicialmente en el entorno urbano el yeísmo. A diferencia del hipotético seseo, del que hay indicios en Madrid desde el s. XVI, aquel no tiene reflejo escrito en el corpus hasta el XIX. Se encuentra no solo en la ciudad de Madrid, sino también en Alcalá de Henares, cosa que no sorprende, pues no en vano tenía el título de ciudad, con larga tradición universitaria, cabeza de partido y una fluida comunicación con la capital, por lo que su espectro sociolingüístico difiere del de otras localidades.

Otros fenómenos, en cambio, como la aspiración y eventual pérdida de la /s/ en coda silábica, se dan tanto en la ciudad como en zonas rurales, no solo al sur de la capital, sino también en la zona más septentrional (Montejo de la Sierra), en este último espacio, en la segunda mitad del s. XIX. La pronunciación interdental de -/d/ final es común en la capital (Madriz, Madrid, 1741) y los pueblos, incluso de la zona meridional (Huiz, Parla, 1816). La neutralización de líquidas se da en las zonas rurales y la capital, y es un fenómeno frecuente extendido en todas las épocas y áreas de la Comunidad. Normalmente está motivado por procesos de asimilación (artar, verbar) y disimilación. Se asocian más a una variedad meridional, pero está registrado en nuestro corpus incluso en zonas norteñas (Montejo de la Sierra, Buitrago del Lozoya).

La confusión gráfica de implosivas en grupos consonánticos cultos es general en todo el español y se puede explicar por el predominio de la imagen fónica respecto a la visual. Indican indefinición y debilitamiento de las consonantes implosivas, y afecta a todo el espacio de la CM. Este fenómeno es innovador y tradicional según los casos; por ejemplo, setiembre, otubre llegan a mano profesional, y son mayoritarias (hay 92 casos de setiembre por 79 de septiembre en CODEA en los ss. XVI-XVIII). A partir de las normas académicas del s. XIX, estas formas quedan fuera de lo estandarizado pero se siguen viendo en la documentación. Resulta significativa la indefinición de la implosiva, a juzgar por casos como dicne ‘digne’ (Alcalá de Henares), o pracmáticas ‘pragmaticas' (Buitrago del Lozoya). 


\section{RELACIÓN CON OTROS ESPACIOS DIALECTALES}

En primer lugar, resulta evidente que algunos de los fenómenos de consonantismo avanzado, como el debilitamiento de -/d/- intervocálica (llegao 'llegado') están actualmente en toda la zona central, sobre todo en hablantes poco instruidos. Otros se han señalado en toda la región de Castilla La Nueva, como la confusión entre /k/-/g/ garpa

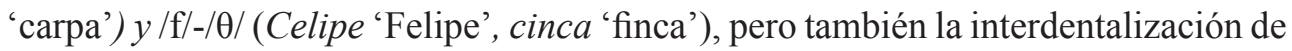
-/d/ (parez), que se da en Madrid y otras provincias como Cuenca y Toledo (Moreno Fernández 2004: 216) ${ }^{37}$. Un fenómeno de la /s/ implosiva, aparte de conocer, como es sabido, una amplia extensión en las hablas meridionales, está presente también en provincias como Ávila, Salamanca y norte de Madrid, de acuerdo con los datos del ALPI (García Mouton y Moreno Fernández 1994: 127).

Un proceso innovador como la neutralización de líquidas se ha atribuido a la zona oriental de la Comunidad de Madrid, en consonancia con la provincia cercana de Guadalajara (ibídem: 221); en concreto, se ha encontrado este fenómeno en posición final de palabra en la zona nordeste, en las localidades de Algete, Torrelaguna, Paracuellos y Talamanca (Ruiz Martínez 2000: 245). Como ya se citó, la lateralización de /r/, por ejemplo en infinitivos, aparece muy reducida en el ADiM (2015), donde también se documenta la neutralización en el este. Sin embargo, en los documentos históricos encontramos testimonios en el área más septentrional (Buitrago del Lozoya, verbar 'verbal' en 1865 y huélfana en 1830) y occidental (El Escorial, artar 'altar' en h. 1770). Esto indica, por lo tanto, que el fenómeno ha tenido cabida en toda la región, aunque en época más reciente se haya conservado más en la zona oriental.

Cabe destacar la coincidencia en las soluciones fonéticas del Norte de la Comunidad de Madrid con las de Castilla-La Mancha, como sucede, por ejemplo, en palancana, que la documentación del siglo XIX localiza en Montejo de la Sierra. Del mismo modo, esta variante se encuentra en $A D i M$ (2015) en la Sierra Norte en Mangirón y Buitrago del Lozoya). En el ALeCMan la variante con sorda /k/ está generalizada en todas las provincias, lo que podría apuntar a que en el pasado esta solución estuviera más extendida en la Comunidad de Madrid. También encuentra continuidad en el espacio limítrofe de Castilla-La Mancha ceajo, una voz que nuestros documentos solo muestran en una localidad norteña cercana a Guadalajara y que el ALeCMan atestigua en el centro-este de esta provincia, así como en el norte de Cuenca. Por el contrario, la forma cegajo, que consideramos más antigua, se

37 Los datos del ALeCMan confirman esta extensión de la interdental. En el mapa Fon. 34, «Una pared», esta solución aparece en la mayor parte de Guadalajara y algunos puntos de Cuenca, así como en dos localidades del noreste de Toledo. 
encuentra en espacios discontinuos y más alejados de la Comunidad de Madrid (este de Guadalajara, este de Cuenca, suroeste de Toledo y este de Ciudad Real). En cambio, no tiene correlato en el ALeCMan la forma guchillo, salvo algunos puntos aislados de Guadalajara y Ciudad Real.

Son las variantes sometidas a variación frecuente en la lengua popular las que nos proporcionan información geográfica, pues estas no alternan de manera aleatoria, sino que se concentran en determinados espacios contiguos; este podría ser el caso de taurete, localizado en Montejo de la Sierra y registrado en el ALeCMan en el oeste de Guadalajara. En otros casos, hay variantes que se muestran actualmente en zonas relativamente distantes de la Comunidad de Madrid, como cofaina 'jofaina, palangana', que solo aparece en sendos puntos del sur de Toledo y el sureste de Cuenca (ALeCMan, mapa 576 palancana).

Si comparamos los datos de los documentos con los de los estudios sincrónicos, parece que el yeísmo se ha generalizado antes en las ciudades de toda el área central castellana, lo que encaja con la tendencia observada en el siglo XIX, donde hay más casos en la capital y Alcalá de Henares que en los pueblos de la Comunidad.

Como se ha visto, estos y otros fenómenos fonéticos innovadores no son exclusivos de la Comunidad de Madrid, y los atlas lingüísticos elaborados en el siglo XX permiten señalar una extensión que, al menos en parte, alcanza al español central. En una perspectiva diacrónica, la documentación en materiales de archivo de estos mismos rasgos avanzados en el consonantismo demuestra que no se trata de fenómenos difundidos recientemente en tal área central y, más precisamente, en la Comunidad de Madrid. Estos materiales son especialmente valiosos por la extraordinaria rareza de la plasmación por escrito de tales fenómenos. Solo un trabajo concienzudo y, en este caso, afortunado, ha hecho posible que afloren numerosos testimonios de fenómenos que corresponden a la lengua oral y que suponemos solo difundidos en el pasado en los registros más populares, precisamente los que corresponden a personas que no suelen dejar huella en la escritura.

\section{CONCLUSIONES}

El examen de la documentación de los pueblos nos ha permitido conocer mejor cómo se configura el habla de la Comunidad de Madrid a lo largo del tiempo. Así, aparte de la interdependencia con la capital, se aprecia la formación de áreas comarcales más restringidas. Es el caso de la Sierra Norte, cuyo núcleo es la localidad de Buitrago, estratégica en el camino de Francia, zona de acantonamiento militar, con juzgado de paz, para asuntos económicos, y desde donde se emiten órdenes (de leva, aprovisionamiento, 
busca y captura de bandoleros y malhechores) a los pueblos vecinos como Piñuécar, Gandullas o Puebla de la Sierra. Observamos una diferencia cultural significativa, que ahora nos permite conjeturar la formación de espacios sociolingüísticos concéntricos: (1) la ciudad de Madrid, con sus contrastes sociales; (2) los pueblos más importantes, en los que hay autoridades civiles y militares, cirujano, médico, maestro, y en ellos se emiten documentos relativamente estandarizados en cuanto a los usos lingüísticos; por ejemplo, Alcalá de Henares, con título de ciudad desde 1687, sería un caso de localidad más poblada de lo habitual, aunque limitada en su importancia a partir del s. XIX; y (3) los pueblos más pequeños, en los que hay un pedáneo o un alcalde de escasísima instrucción, apenas capaz de escribir una breve nota de recepción de órdenes (Piñuécar, La Hiruela, Garganta de los Montes). Estos núcleos de población han estado en interacción constante y cambiante con la ciudad de Madrid, en cuatro fases sucesivas: (1) en el s. XV, ese espacio rural que nos pintaba allá por el 1200 el Fuero del concejo, se transforma en una villa importante para la estrategia de los reyes contra la nobleza, como se aprecia en la Crónica de Enrique IV de Enríquez del Castillo (Rábade Obradó 2009); no fue casualidad, contra lo que se ha dicho, que le fuera otorgada la capitalidad del reino en 1561; (2) desde este momento tiene lugar un importante aumento de la población, no tanto por el crecimiento vegetativo como por la afluencia de gentes de todos los lugares; en esta etapa los pueblos de la «tierra de Madrid» tienen un cierto papel en la conformación de la vida y, suponemos, de la lengua capitalina; (3) en el s. XVIII se construye ya un verdadero espacio urbano, y (4) es entonces cuando se empieza a producir una influencia notable sobre el entorno rural, dentro de un proceso imparable que superará en el s. XIX el ámbito regional.

Dentro de este marco evolutivo de la villa de Madrid se explican mejor los rasgos de tinte sociolingüístico bajo que muestran nuestros documentos, y que ahora afloran gracias a la exhumación de los importantes fondos de beneficencia de la Inclusa y el Refugio. Sin embargo, esta marca sociocultural de gran parte de los fenómenos aquí recogidos no merma la importancia diatópica que tiene el hecho de documentarlos en escritos madrileños de los ss. XVII al XIX, entre otras razones, porque bastantes de ellos llegan a personas de nivel socioeducacional medio, como se ha visto en el mencionado «seseo» madrileño recientemente documentado para los ss. XVIII y XIX (Vázquez Balonga y Sánchez-Prieto Borja 2015).

Es cierto que muchos de los rasgos aquí señalados, no se restringen a Madrid y su tierra, sino que se dan en todo el territorio hispánico, casi siempre en hablantes poco instruidos. Sin embargo, es la combinación de rasgos, el conjunto de los que se dan en un espacio, lo que la caracteriza y posiciona lingüísticamente dentro de la dialectología histórica. En el plano específico del registro escrito, tiene un papel determinante la 
impericia de muchos scriptores, que encuentra un paralelo significativo con los usos de los hablantes actuales madrileños que no dominan la ortografía.

Gracias a la indagación en los archivos, no siempre fácil, es posible alcanzar un conocimiento más ponderado del habla histórica de Madrid y su entorno. En este sentido, cabe destacar la modificación del punto de vista tradicional acerca de no pocos fenómenos fonéticos relativos al consonantismo; así, puede verse cómo rasgos que se consideraban meridionales o recientes, como la neutralización /r/-/1/ en coda silábica o la pérdida de /d/ fricativa tanto para -ado como - ada, alcanzan una extensión superior a la que suele señalarse y una profundidad histórica hasta ahora no reconocida para la ciudad de Madrid y los pueblos de la Comunidad.

\section{BIBLIOGRAFÍA}

ADiM= García Mouton, P. e I. Molina Martos (2015): Atlas Dialectal de Madrid. http://adim.cchs.csic.es/es/adim/presentacion

ALeCMan= García Mouton, P. y F. Moreno Fernández (2003): Atlas Lingüístico y Etnográfico de Castilla-La Mancha (ALeCMan). http://www.linguas.net/alecman/ Almeida CABREJAs, B. (2014): «Escriptores con bajo y medio nivel socioeducacional en documentos del siglo XIX del Archivo Municipal de Alcalá de Henares», in R. Díaz Moreno y B. Almeida (coords.), Estudios sobre la historia de los usos gráficos en español. Lugo: Axac, pp. 167-210.

Alonso, A. (1962): «Sobre la-s final de sílaba en el mundo hispánico», in Enciclopeia Lingüística Hispánica, I. Madrid: CSIC, pp. 47-53.

Alvar, M. (1955): «Las hablas meridionales de España y su interés para su lingüística comparada», RFE, XXXIX, pp. 284-313.

Alvar EzQuerra, M. (2011): Diccionario de madrileñismos. Madrid: La Librería.

Álvarez Martínez, M. Á. (2004): «Extremeño», in M. Alvar Ezquerra (coord.): Manual de Dialectología Hispánica. El español de España. Barcelona: Ariel, pp. 171-182.

BlANCO, M. (2007): Aproximación a la cronología de las transformaciones funcionales de labiales y sibilantes del español. Santiago de Compostela: Universidad de Santiago de Compostela (Lalia. Series Maior).

Bustos GisBert, Eugenio y R. SANTIAGo (2000): «Para un nuevo planteamiento de la llamada «norma madrileña» (siglos XVI y XVII)», in María Teresa Echenique y Juan Pedro Sánchez Méndez (coords.), Actas del V Congreso Internacional de Historia de la Lengua Española (Valencia, del 31 de enero al 4 de febrero del 2000). Madrid: Arco Libros, pp. 1123-1136. 
CODEA = Corpus de Documentos Españoles Anteriores a $1800(C O D E A+2015)$. http://www.corpuscodea.es/

$C O R D E=$ Real Academia de la Lengua Española: Corpus Diacrónico del Español . http://www.rae.es/recursos/banco-de-datos/corde

FernándeZ-Ordoñez, I. (2006): «Del Cantábrico a Toledo: El 'neutro de materia' hispáncio en un contexto románico y tipológico (primera parte)», Revista de Historia de la Lengua Española, 1, pp. 29-81.

García Mouton, P. e I. Molina Martos (2017): Las hablas rurales de Madrid. Berna: Peter Lang.

García Mouton, P. y F. Moreno Fernández (1994): «El Atlas Lingüístico y Etnográfico de Castilla-La Mancha. Materiales fonéticos de Ciudad Real y Toledo», in Geolingüistica. Trabajos europeos. Madrid: CSIC, pp. 111-152.

GonZÁLez OlLÉ, F. (1995): «Un caso de aplicación (1560) del privilegio lingüístico alfonsino», Cahiers d'Études Hispaniques Médiévales, 20, pp. 269-343.

Cestero Mancera, A. M., I. Molina Martos y F. Paredes García (2015): Patrones sociolingüísticos de Madrid. Berna, Peter Lang.

Molina MARTos, Isabel (2001): «Geografía y estratificación social de un cambio fonético: la -d- en español peninsular», Verba 28, pp. 81-99.

Molina Martos, I. (2013): «Yeísmo madrileño y convergencia dialectal campo/ ciudad», in R. Gómez e I. Molina Martos (eds.), Variación yeísta en el mundo hispánico. Madrid/Frankfurt am Main: Iberoamericana, pp. 93-110.

Moreno Fernández, F. (2004): «Castilla La Nueva», en M. Alvar (dir.): Manual de Dialectología Hispánica. El español de España. Barcelona: Ariel, pp. 213-232. NAvarro TomÁs, T. (1975): «Áreas geográficas de consonantes finales», in Capítulos de geografía lingüistica de la Península Ibérica, pp. 187-191.

$N T L L E=$ Real Academia Española de la Lengua: Nuevo Tesoro Lexicográfico de la Lengua Española. http://www.rae.es/recursos/diccionarios/diccionariosanteriores-1726-1992/nuevo-tesoro-lexicografico

PAREDES GARCÍA, F. (1999): «La ortografía en las encuestas de disponibilidad léxica», Reale. Revista de Estudios de Adquisición de la Lengua Española 11, pp. 75-97.

Paredes García, F. (2004): Textos para la Historia del Español III. Archivo Municipal de Alcalá de Henares. Alcalá de Henares: Servicio de Publicaciones de la Universidad de Alcalá.

Paredes García, F. (2010): Textos para la Historia del Español V. Archivo Municipal de Daganzo. Alcalá de Henares: Servicio de Publicaciones de la Universidad de Alcalá. 
Pascual, José Antonio (1998): «El revolucionario conservadurismo del español norteño: A propósito de la evolución e la s implosiva», in I. Andrés-Suárez y L. López Molina (eds.): Estudios de lingüistica y Filología españolas: homenaje a Germán Colón. Madrid: Gredos, pp. 387-400.

RÁBADE OBRADÓ, M. P. (2009): «Escenario para una corte real: Madrid en tiempos de Enrique IV», E-Spania. Revue interdisciplinaire d'études hispaniques médiévales et modernes. https://journals.openedition.org/e-spania/18883

Ruiz Martínez, A. M. (1999): Estudio lingüistico del nordeste de la Comunidad de Madrid. Tesis Doctoral. Universidad de Alcalá.

Sánchez-Prieto Borja, P. y A. Flores Ramírez (2005): Textos para la Historia del Español. Archivo Regional de Madrid. Alcalá de Henares: Servicio de Publicaciones de la Universidad de Alcalá.

SÁnchez-Prieto Borja, P. y D. VÁzquez Balonga (2017): «Hacia un corpus de beneficencia en Madrid (siglos XVI-XIX)», Scriptum Digital 6, pp. 83-103.

Torrens Álvarez, María Jesús (2002): Edición y estudio lingüístico del Fuero de Alcalá (Fuero Viejo). Alcalá de Henares: Fundación Colegio del Rey.

VÁzQuez BAlonga, Delfina (2014): Textos para la Historia del Español VIII. Archivo Municipal de Arganda del Rey. Alcalá de Henares: Servicio de Publicaciones de la Universidad de Alcalá.

VÁZQUez BALONGA, D. (2015): Léxico en al documentación de Toledo y Madrid (siglos XVI y XVII). Tesis doctoral, Universidad de Alcalá.

VÁzquez Balonga, D. y P. SÁnchez-Prieto Borja (2015): «iSeseo en el centro peninsular'», Revista de Historia de la Lengua Española 10, pp. 201-207. 